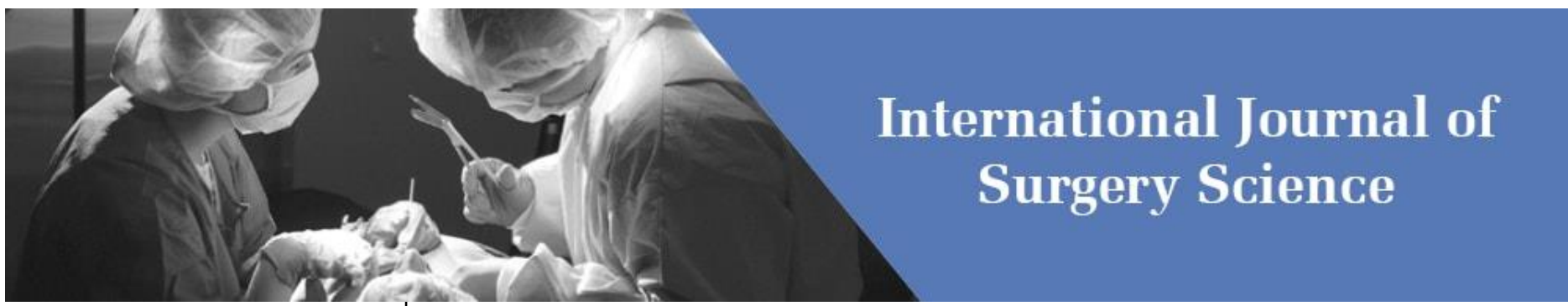

E-ISSN: 2616-3470

P-ISSN: 2616-3462

(C) Surgery Science www.surgeryscience.com

2019; 3(4): 223-225

Received: 16-08-2019

Accepted: 20-09-2019

Dr. Vikash Kumar

Consultant, Department of General Surgery, Asian Dwarkadas Jalan

Hospital, Dhanbad

Jharkhand, India

Dr. Vaibhav Kant Baderiya Assistant Professor, department of general surgery, CIMS medical college, Bilaspur, Chhattisgarh, India
Corresponding Author: Dr. Vikash Kumar Consultant, Department of General Surgery, Asian Dwarkadas Jalan Hospital, Dhanbad

Jharkhand, India

\section{Assessment of preoperative patient factors in early prediction of difficult laparoscopic cholecystectomy: A single institution study}

\author{
Dr. Vikash Kumar and Dr. Vaibhav Kant Baderiya
}

DOI: https://doi.org/10.33545/surgery.2019.v3.i4d.245

\section{Abstract}

Background: Laparoscopic cholecystectomy is the most common elective surgery performed by general surgeon. In certain situations lap cholecystectomy which is supposed to be simple and safe procedure becomes very difficult and unsafe. Therefore early prediction of difficulty level before elective surgeryis an important aspect so that patient can be counseled about the risks and outcomes.

Methods: 80 cases of lap cholecystectomy operated by a single surgeon is included in the study. there are total 15 score from history, clinical, and sonological finding, they were evaluated and scored on the basis of scoring system of randhawa and Pujahari. Score up to 5 is defined as easy, 6-10 as difficult and 11-15 as very difficult.

Result: the present study found that age, BMI, previous H/O hospitalization, palpable GB clinically, USG finding of increased GB wall thickness, impacted stone are significant factors that result in difficult and very difficult lap cholecystectomy. Conversion to open procedure was seen in $7.5 \%$ cases.

Conclusion: the scoring system had a positive predictive falue of $83 \%$ with sensitivity of $94 \%$.

Keywords: Lap chole, predictive factors, scoring system

\section{Introduction}

Laparoscopic cholecystectomy is the most common elective surgery performed by general surgeon, it is the gold standard procedure for symptomatic gall stone disease for its minimally invasive, less post-op pain, early recovery.in certain situations lap cholecystectomy which is supposed to be simple and safe procedure becomes very difficult and unsafe ${ }^{[1]}$, these situations are in congenital anatomical anomaly in duct, artery ${ }^{[2]}$. acute inflammation with gangrenous GB, dense adhesions in calots triangle, small fibrotic GB, cholecystoenteric fistula; some other patient factors ${ }^{[3]}$ like old age, male sex, obesity, attacks of acute cholecystitis, prior upper abdominal surgery, certain USG finding like thickened GB wall, impacted stone in neck, pericholecystic fluid, further increase difficulty level of lap cholecystectomy ${ }^{[4]}$.

Therefore early prediction of difficulty level before elective surgeryis an important area which can help a general surgeon so that necessary planning can be done to improve patient outcomes and patient can be counseled pre-operatively regarding chances of conversion to open cholecystectomy and risk of surgery.

\section{Methods}

A prospective study was carried out in department of general surgery in asian dwarkadas jalan hospital in dhanbad Jharkhand. Patient who underwent lap cholecystectomy irrespective of age between july 2018 to july 2019 were included in this study.

Exclusions-patient with CA GB, CBD stone, Dilated CBD, obstructive jaundice, patient not giving consent for part of this study were excluded, conversion due to equipment failure.

Study design: All the case of lap cholecystectomy operated by a single laparoscopic surgeon was included in this study, a written informed consent was taken from the study participants after explaining the procedure, a proper workup of every case which includes demographical details, history, clinical finding and investigations. Each patient was given a score as per scoring system of radhawa and pujahari one day prior to surgery 
Table 1: Randhawa and Pujahari scoring system.

\begin{tabular}{|c|c|c|c|}
\hline History & & & Max score \\
\hline age & $<50(0)$ & $>50(1)$ & 1 \\
\hline sex & Female(0) & Male(1) & 1 \\
\hline h/o hospitalisation & No (0) & Yes(4) & 4 \\
\hline Clinical & & & 2 \\
\hline BMI & $<25(0)$ & $\begin{array}{c}25-27.5(1) \\
>27.5(2)\end{array}$ & 1 \\
\hline Palpable GB & No(0) & Yes(1) & 2 \\
\hline Abdominal scar & No(0) & $\begin{array}{c}\text { Infraumbilical(1) } \\
\text { Supraumbilical(2) }\end{array}$ & 2 \\
\hline USG & & & 1 \\
\hline Wall thickness & Thin(0) & $>4 m m(2)$ & 1 \\
\hline Impacted stone & No (0) & Yes (1) & Yes(1) \\
\hline Pericholecystic collection & No (0) & & 2 \\
\hline & & & \\
\hline
\end{tabular}

\section{Max score-15}

Score upto 5 is considered as easy, 6-10 is difficult, 11-15 as very difficult.

All the intraoperative events were recorded and timing were noted from the first port site incision until the last port closure, surgical procedure was categorized post operatively into easy, difficult, and very difficult on the basis of time taken in minutes, bile/stone spillage, injury to duct and artery, and conversion to open cholecystectomy. Same surgical procedure and technique followed in every patient.

Table-2: Easy/difficult criteria for laparoscopic cholecystectomy as defined by randhwa JS et al ${ }^{[5]}$

\begin{tabular}{|c|c|c|c|}
\hline Factors & Easy & Difficult & Very difficult \\
\hline Time taken in minutes & $<60$ & $60-120$ & $>120$ \\
\hline Bile/stone spillage & No & Yes & Yes \\
\hline Injury to duct/artery & No & Only duct & Both \\
\hline Conversion to open sx & No & No & Yes \\
\hline
\end{tabular}

Stastical Analysis: data so obtained is analysed using SPSS -16 data analysis software

Chi-square test was used for the analysis and a $\mathrm{P}$ value of less than or equal to 0.05 was considered stastically significant.

\section{Results}

Laparoscopic cholecystectomy were performed in 80 patient at our hospital during this time period, out of which 18 were comes to be difficult, 8 were very difficult, 54 were comes out to be easy. Rate of conversion were $7.5 \%$.majority of patients was females and majority was below age of 50 years. 28 patient was obese, previous surgery was present in 28 patients $(20$ with tubeligation and 8 with LSCS) all had infraumbilical scar, $\mathrm{H} / \mathrm{O}$ previous admission was present in 21 patient, GB was palpable in 5 patient, on USG GB wall thickness was normal in 64 pts and increased in $16 \mathrm{pts}$, impacted stone in $16 \mathrm{pts}$, pericholecystic fluid in 3 patients.

Associated comorbidity (HTN and DM) was present in 18 pts.

Table-3: Correlation of pre-operative score and outcome

\begin{tabular}{|c|c|c|c|c|}
\hline Pre-op score & Easy & Difficult & Very difficult & Total \\
\hline $0-5$ & 51 & 8 & 2 & 61 \\
\hline $6-10$ & 3 & 11 & 4 & 18 \\
\hline $11-15$ & - & - & 1 & 1 \\
\hline Total & 54 & 19 & 7 & 80 \\
\hline
\end{tabular}

Table 4: Comparison of preoperative risk factors and surgical outcome in this study with that conducted by Randhawa and Pujahari

\begin{tabular}{|c|c|c|c|c|c|}
\hline \multirow[b]{2}{*}{ Risk factors } & \multirow[b]{2}{*}{ Level } & \multicolumn{2}{|c|}{ Per-op outcome } & \multirow[b]{2}{*}{ P-value of current study } & \multirow[b]{2}{*}{ P-Value of R. pujahari study } \\
\hline & & $\begin{array}{l}\text { No. of (difficult + very } \\
\text { difficult) }\end{array}$ & $\begin{array}{c}\text { No. of } \\
\text { easy }\end{array}$ & & \\
\hline \multirow{2}{*}{ Age } & $<50$ & \begin{tabular}{l|l}
12 & \\
\end{tabular} & 50 & \multirow{2}{*}{$<0.05$} & \multirow{2}{*}{$>0.05$} \\
\hline & $>50$ & 15 & 3 & & \\
\hline \multirow{2}{*}{ Sex } & \multirow{2}{*}{$\begin{array}{l}\text { female } \\
\text { male }\end{array}$} & 17 & 35 & \multirow{2}{*}{$>0.05$} & \multirow{2}{*}{$>0.05$} \\
\hline & & 9 & 19 & & \\
\hline \multirow{2}{*}{ BMI } & \multirow{2}{*}{$\begin{array}{l}\text { Nonobese } \\
\text { Obese }\end{array}$} & 8 & 46 & \multirow{2}{*}{$<0.05$} & \multirow{2}{*}{$<0.05$} \\
\hline & & 13 & 15 & & \\
\hline \multirow{2}{*}{ Previous Surgery } & \multirow{2}{*}{$\begin{array}{l}\text { Nil } \\
\text { Yes }\end{array}$} & 12 & 40 & \multirow{2}{*}{$>0.05$} & \multirow{2}{*}{$>0.05$} \\
\hline & & 14 & 14 & & \\
\hline \multirow{2}{*}{ Hospitalisation } & No & 7 & 52 & \multirow{2}{*}{$<0.05$} & \multirow{2}{*}{$<0.05$} \\
\hline & Yes & 14 & 7 & & \\
\hline \multirow{2}{*}{ Gb Palpable } & \multirow{2}{*}{$\begin{array}{l}\text { Not palpable } \\
\text { palpable }\end{array}$} & 17 & 58 & \multirow{2}{*}{$<0.05$} & \multirow{2}{*}{$<0.05$} \\
\hline & & 4 & 1 & & \\
\hline \multirow{2}{*}{ Gb Wall Thickness } & Normal & 8 & 56 & \multirow{2}{*}{$<0.05$} & \multirow{2}{*}{$<0.05$} \\
\hline & Increased thickness & 13 & 3 & & \\
\hline \multirow{2}{*}{ Impacted Stone } & Nil & 12 & 52 & \multirow{2}{*}{$<0.05$} & \multirow{2}{*}{$>0.05$} \\
\hline & Yes & 9 & 7 & & \\
\hline \multirow{2}{*}{ Pericholecystic Fluid } & Nil & 19 & 58 & \multirow{2}{*}{$>0.05$} & \multirow{2}{*}{$>0.05$} \\
\hline & Yes & 2 & 1 & & \\
\hline
\end{tabular}

\section{Discussion}

In this study 80 patients with various pre-operative parameters including age, sex, obesity, previous $\mathrm{H} / \mathrm{O}$ hospitalization, previous surgery, palpable GB, USG finding like GB wall 
thickness, impacted stone, pericholecystic fluid, was studied. these parameters was studied and correlated with per operative difficulty prediction which will help the surgeon to prevent the complications beforehand .

In this study conversion rate was $7.5 \%$, this result is comparable to several other study like Randhawa et al (2009) [5] with conversion rate of $1.3 \%$, Gupta $\mathrm{N}$ et al (2013) [6] $4.3 \%$, Vikalp gupta et al (2017) ${ }^{[7]} 6 \%$, the universal accepted range of conversion is $2-15 \%$

Age is risk factor for difficult lap cholecystectomy ${ }^{8} \mathrm{In}$ the present study, majority of patient were in the age group $<50$ years $(62$ patient) and only 18 patient were $>50$ years.in this study we found significant correlation between age and difficult lap cholecystectomy with p-value $<0.05$

Male sex has been described to be associated with difficult $\mathrm{LC}^{9}$. but in present study 28 were males and 52 were females, out of 28 males 9 were comes out to be difficult and very difficult category and it doesn't show significant correlation.

Obesity poses a great challenge to the safe and timely completion of the procedure due to various factors in from abdominal access, dissection of fatty calots ${ }^{[10]}$. In the present study 28 patient were obese out of which 13 were comes out to be difficult and very difficult category, and it shows significant correlation with p-value $<0.05$.

History of hospitalization due to episodes of cholecystitis has correlation with the difficulty level of cholecystectomy as it may lead to increased gall bladder wall thickness and causing scarring and fibrosis of $\mathrm{GB}^{[11]}$.In this study we found significant correlation between pre-operative hospitalization and difficulty level intraoperatively

In this study we found significant correlation between clinically palpable GB and difficult lap cholecystectomy as in study by randhwa and pujahari ${ }^{5}$.clinically palpable $\mathrm{GB}$ is seen in empyema, mucocele, or adhesion of GB with omentum. Increased GB wall thickness is also linked with difficult lap cholecystectomy with difficult GB dissection as well as manipulation of GB becomes difficult ${ }^{12}$.in this study we found significant correlation between GB wall thickness and difficult lap cholecystectomy.

History of previous surgery especially upper abdominal may pose difficulty due to unwanted adhesion around the umbilicus and peri gall bladder area ${ }^{[13]}$. in this study 28 patient had $\mathrm{H} / \mathrm{O}$ previous surgery but we don't find any significant correlation between the two, we also not found any significant correlation between pericholecystic fluid with difficult lap cholecystectomy. impacted stone on USG having significant correlation with difficult lap cholecystectomy ( $\mathrm{p}$ value $<0.05$ ).

Difficult dissection at calots triangle may cause bleeding from GB bed, difficult application of clips in a wide cystic duct, cbd injury, tear of cystic artery, tear of GB with spillage of bile and stone in peritoneal cavity.it was a significant predictor in previous studies ${ }^{[14]}$ and in our study also.

This study shows that pre-operative scoring system can predict operative difficulty for lap cholecystectomy to a reliable extent. This system can also aid in recognition of cases where an open cholecystectomy should be considered and patient can be counseled pre-operatively.

\section{Conclusion}

Laparoscopic cholecystectomy is the procedure of choice for management of symptomatic gall stone disease which could at times is an easy procedure conducted in a short time whereas occasionally, it can be difficult procedure extending to a longer duration of time .pre-operative prediction of a difficult laparoscopic cholecystectomy can help the surgeon to better prepare for risk factors or intra-operative complications and can help to predict the risk of conversion to open cholecystectomy.

\section{References}

1. ayant hussain, saurabh pathak, huma firdaus et al. Assessment of operative predictors for difficulty in laparoscopic cholecystectomy; IJCMR. 2016; 3(4).

2. Singh K, ohri A. difficult lap cholecystectomy: A large series from north India. Ind. J surg. 2006; 68(4):205e8.

3. Abdel baki. NA, Motawei MA, Soliman KE, et al. Preoperative prediction of difficult lap cholecystectomy using clinical and USG parameters JMRI. 2006; 27(3):102e7.

4. Kama NA, kologlu M, Doganay et al. A risk score for conversion from laparoscopic to open cholecystectomy Am J Surg. 2001; 181:520e5.

5. Randhawa JS, Pujahari AK. pre-operative prediction of difficult lap chole: a scoring method. Indian J Surg. 2009; 71:198-201.

6. Gupta N, Ranjan G, Arora MP, Goshwami B, Chaudhary P, Validation of a scoring system to predict difficult lap cholecystectomy. Int J surg. 2013; 11:1002-06.

7. Gupta V et al. Pre-operative prediction of difficult laparoscopic cholecystectomy-A scoring system IJSR. 2017; 13:1041-43.

8. Simopoulos C, Botaitis S, Polychronidis A, Tripsianis G, Karayiannakis AJ. Risk factor for conversion of lap cholecystectomy to open cholecystectomy surg Endosc. 2005; 19:905-9.

9. O leary DP, Myers E, Waldron D, Coffey JC. Beware the contracted GB: Ultrasonic predictor of conversion. Surg. 2013; 11:187-90.

10. Rosen M, Brody F, Ponsky J. Predictive factors for conversion of laparoscopic cholecystectomy. Am J Surg. 2002; 184:254-8.

11. Rattner DW, Fergusonc, warshaw AL. Factors associated with successful laparoscopic cholecystectomy for acute cholecystitis. Ann Surg. 1993; 217:233-6.

12. Fried GM, Barkun JS, Sigman HH, Joseph L, Clas D, Garzon J, et al. Factors determining conversion to laparotomy in patients undergoing laparoscopic cholecystectomy. Am J. Surg. 1994; 167:35-9.

13. Botaitis S, Pitiakoudis M, Perente S, Tripsianis G, Polychronidis A, Simopoulos C. Laparoscopic cholecystectomy in acute cholecystitis: an analysis of the risk factors. SAfr J Surg. 2012; 50:62-4.

14. Nachnani J, Supe A. Pre-operative prediction of difficult lap cholecystectomy using clinical and ultrasonographic parameters, Indian J Gastroentro. 2005; 24(1):16-18. 